\title{
Enhancing farmers' agency in the global crop commons through use of biocultural community protocols
}

\author{
Michael Halewood ${ }^{1,15}$ - Ana Bedmar Villanueva ${ }^{1} \cdot$ Jazzy Rasolojaona ${ }^{2} \cdot$ Michelle Andriamahazo $^{3}$. \\ Naritiana Rakotoniaina ${ }^{4} \cdot$ Bienvenu Bossou ${ }^{5} \cdot$ Toussaint Mikpon $^{6} \cdot$ Raymond Vodouhe $^{1} \cdot$ Lena Fey $^{7} \cdot$ Andreas Drews $^{7}$. \\ P. Lava Kumar ${ }^{8}$. Bernadette Rasoanirina ${ }^{9} \cdot$ Thérèse Rasoazafindrabe $^{9} \cdot$ Marcellin Aigbe $^{10}$. Blaise Agbahounzo ${ }^{11}$. \\ Gloria Otieno ${ }^{12} \cdot$ Kathryn Garforth ${ }^{13} \cdot$ Tobias Kiene $^{14} \cdot$ Kent Nnadozie $^{14}$
}

Accepted: 6 October 2020 / Published online: 6 January 2021

(c) The Author(s) 2021

\begin{abstract}
Crop genetic resources constitute a 'new' global commons, characterized by multiple layers of activities of farmers, genebanks, public and private research and development organizations, and regulatory agencies operating from local to global levels. This paper presents sui generis biocultural community protocols that were developed by four communities in Benin and Madagascar to improve their ability to contribute to, and benefit from, the crop commons. The communities were motivated in part by the fact that their national governments' had recently ratified the Plant Treaty and the Nagoya Protocol, which make commitments to promoting the rights of indigenous peoples, local communities and farmers, without being prescriptive as to how Contracting Parties should implement those commitments. The communities identified the protocols as useful means to advance their interests and/or rights under both the Plant Treaty and the Nagoya Protocol to be recognized as managers of local socio-ecological systems, to access genetic resources from outside the communities, and to control others' access to resources managed by the community.
\end{abstract}

Keywords Biocultural community protocols $\cdot$ Access and benefit-sharing $\cdot$ Farmers' communities $\cdot$ Global crop commons · Crop genetic diversity

\section{Introduction}

Crop genetic resources constitute a 'new' global commons, with a highly complex, internationally distributed, modular architecture, characterized by multiple layers of activities of

Michael Halewood

m.halewood@cgiar.org

Alliance of Bioversity International and CIAT, Rome, Italy

2 Natural Justice, Cape Town, South Africa

3 Ministry of Agriculture (MinAgri), Antananarivo, Madagascar

4 Service d'Appui à la Gestion de l'Environnement (SAGE), Antananarivo, Madagascar

5 ONG Cercle de Sauvegarde des Ressources Naturelles (CeSaReN), Cotonou, Benin

6 Institut National des Recherches Agricoles du Benin (INRAB), Cotonou, Benin

7 ABS Capacity Development Initiative, Bonn, Germany farmers, genebanks, public and private research and development organizations, and norm setting organizations operating from local to global levels (Dedeurwaerdere 2012).

Recent literature has analyzed the extent to which international policies and laws support or undermine the

8 International Institute of Tropical Agriculture (IITA), Ibadan, Nigeria

9 FaMa Cooperative, Antananarivo, Madagascar

10 NGO Jeunesse Sans Frontières, Cotonou, Benin

11 Tori-Bossito, Benin

12 Alliance of Bioversity International and CIAT, Kampala, Uganda

13 Convention on Biological Diversity, Montreal, Canada

14 International Treaty on Plant Genetic Resources for Food and Agriculture, Rome, Italy

15 Alliance of Bioversity International and CIAT, Via dei Tre Denari, 472/a, 00054 Maccarese, Fiumicino, Italy 
production and sustainable use of the genetic diversity comprising the global crop commons (Frison and Coolsaet 2019; Halewood et al. 2012; Kamau and Winter 2013; Wirz et al. 2017; Onwuekwe 2004). The roles of genebanks and formal sector plant breeders in conserving and generating new crop genetic resources are recognized and relatively well incentivized/rewarded under the evolving international legal framework, ${ }^{1}$ and investments in both, while subject to unpredictable fluctuations, remain relatively constant and are likely to increase. ${ }^{2}$ The situation is different with respect to in situ and on farm 'conservation through use' of these resources by farmers, local communities and indigenous peoples (Hodgkin et al. 2013). On one hand, there has been progress in terms of formal recognition in international law of small-scale farmers' contributions to the development and conservation of agricultural biological diversity. ${ }^{3}$ Furthermore, there have been a number of projects to support small-scale farmers as managers/improvers of crop genetic diversity $^{4}$ and a growing body of related literature (Jarvis

\footnotetext{
${ }^{1}$ For examples, the UPOV Conventions and WTO-TRIPS promote plant breeders' rights and patents for plants; the Plant Treaty's Multilateral System of Access and Benefit-sharing supports availability of crop genetic resources for use in plant breeding, and sharing benefits derived from commercialization of new varieties; the FAO-CGIAR In trust Agreements and the Plant Treaty confirm the legal status of crop and forage collections hosted by international organizations and guarantee their availability for use for conservation, breeding, and research for food and agriculture; the Global Crop Diversity Trust, as an essential element of the Funding Strategy of the Plant Treaty, provides financial and technical support for international and national genebanks; and the $2^{\text {nd }}$ Global Plan of Action for Plant Genetic Resources for Food and Agriculture identifies ex situ conservation, on farm conservation and plant breeding as global priorities.

2 Of course, both plant breeding and ex situ conservation would benefit from considerably more investment. Indeed, the $2^{\text {nd }}$ Global Plan of Action decries the reduction of support for plant breeders by many national governments. That said, over the last 40 years, there have been considerable investments in both ex situ conservation and plant breeding (particularly from the private sector with respect to the latter), with promises of new investments, for example, the announcement of 790 million dollars for climate change adaptation, of which a substantial proportion will support plant breeding (https://www.wri.org/ news/2019/09/release-un-summit-new-commitments-over-790-milli on-support-climate-adaptation-over-300) and the ongoing efforts of the Global Crop Diversity Trust to develop a 250 million dollar trust fund to provide in perpetuity support for ex situ crop genetic resources collections.

${ }^{3}$ See footnote 11 below and attendant discussion.

${ }^{4}$ For examples of projects supporting activities in multiple countries see Sowing Diversity $=$ Harvesting Security $(\mathrm{SD}=\mathrm{HS})$, coordinated by Oxfam Novib (https://www.sdhsprogram.org/); Farmers' Pride, coordinated by University of Birmingham and a coalition of partners (https://www.farmerspride.eu/); Diversifood (https://www.diver sifood.eu/project/); Community Biodiversity Development and Conservation - Biodiversity Use and Conservation Programme (CBDCBUCAP), managed by SEARICE (https://www.searice.org.ph/cbdcbucap); Strengthening the scientific basis of in situ conservation of agricultural biodiversity on-farm, coordinated by the International
}

et al. 2011, 2016; de Boef et al. 2013; Pimbert 2011; Brush 2000). On the other hand, however, the level of sustained, systematic support for small-scale farmers' on-farm crop diversity management, and for strengthening their collaborative links with other key actors to be able to play an active role in conserving, using, and improving crop diversity in the globally distributed commons remains quite low.

Indeed, one could argue that small-scale farmers, local communities and indigenous peoples are actually losing agency qua crop diversity managers, partly as an unintended result of impressive technological, organizational and institutional developments in the last 50 years that have altered the scope, function and management of the crop commons. One of these developments is modern plant breeding, which has generated extraordinary benefits for farmers, for local and national economic development and for food security. Another such development has been the creation of a globally linked system of crop genetic resources collections under the auspices of the International Treaty on Plant Genetic Resources for Food and Agriculture (Plant Treaty). Both these extremely positive developments have, inadvertently, tended to draw attention away from the contributions that small-scale farmers can continue to play in conserving, generating, and adding value to crop genetic diversity. This relative diminution of small-scale farmers' roles as diversity managing agents within the crop commons results in lost opportunities for them to access and experiment with crop genetic resources and to partner with other actors (e.g. national and international genebanks, plant breeders) to generate new crop diversity and to add value to that which already exists in the global crop commons for the benefit of all potential users. Climate change is increasing the urgency to address, indirect, this situation, as the generation, availability and use of crop genetic diversity is essential for adapting agricultural production systems to the growing list of biotic and abiotic challenges associated with climate change (Lin 2011; Mijatović et al. 2013; Altieri et al. 2015).

This paper addresses the question: What institutional innovations can enhance farmers' agency in the evolving global crop commons-not by a return to 'the way things were' before the development of modern plant breeding and internationally linked genebanks - but by enabling farmers to take advantage of these developments and to continue to add value to the crop commons through use of their specialized knowledge and experience? In response, the paper presents a portfolio of measures that were designed to promote farmers' agency in this way in Benin and Madagascar. Some of these measures will already be familiar to people working in the area of on farm 'conservation through use'

\section{Footnote 4 (continued)}

Plant Genetic Resources Institute (IPGRI) (https://idl-bnc-idrc.dspac edirect.org/bitstream/handle/10625/22150/112967.pdf?sequence=1). 
of crop diversity, and are described in relevant literature, so we will mention them only in passing. Our primary focus in this paper will be on one particular (original) innovation: sui generis biocultural community protocols which were developed to, among other things, promote farming communities' access to crop genetic resources from elsewhere for experimentation, improvement and management as part of their local production systems.

Biocultural community protocols have been the subject of attention for over 20 years (Shrumm and Jonas 2012; Delgado 2016; LPP 2018). Two common characteristics of most biocultural community protocols are that they (i) affirm the status of the communities concerned as the rightful managers of local natural resources, including genetic resources, and (ii) set out rules controlling extra-community actors' access to genetic materials and traditional knowledge held by community members (Shrumm and Jonas 2012; Delgado 2016; LPP 2018). What sets apart the biocultural community protocols discussed in this paper is that they also promote the rights of communities to facilitated access to crop genetic resources for food and agriculture distributed around the world, and establish practical methods to gain free (or at minimal administrative costs) access to those resources, and to test and integrate them into their production systems.

The paper presents results of a 3-year research and development project-'Mutually Supportive Implementation of the Nagoya Protocol and the Plant Treaty in Benin and Madagascar' - supported by the Darwin Initiative and executed by Bioversity International in partnership with the GIZimplemented ABS Capacity Development Initiative. The objective of the project was to develop national level polices and laws to implement the Nagoya Protocol on Access to Genetic Resources (Nagoya Protocol) and the Plant Treaty in mutually supportive ways, thereby overcoming long standing divisions (witnessed all around the world —not just in these two countries) between environment and agricultural sectors. One of the most challenging aspects of the project was to explore means by which both international agreements could be implemented at community levels that would be truly meaningful/helpful to the local communities addressing immediate needs. Therefore, the biocultural community protocols discussed here were developed to consolidate and codify best practices and lessons learned through the community-level work, and to strengthen and streamline the communities' collective capacity to engage with extracommunity agencies in the future. The protocols' potential in this regard was substantially increased by having them recognized in the national laws implementing the Nagoya Protocol and the Plant Treaty of the two countries, which were developed over the course of the implementation of the project. As such, the protocols represent a point of intersection between efforts to promote community based biodiversity management, participation of farmers in scaled-up participatory crop research, and international and national level efforts to regulate access to their genetic resources and benefit sharing, taking into consideration the extraordinary scientific and organizational developments that have shaped the crop commons over the last decades.

The biocultural community protocols were finalized as the project came to a close. Indeed, two of them were adopted by municipal authorities after the project ended. Their use in practice, therefore, is beyond the scope of this paper.

The project was not originally framed using commonsrelated institutional analysis. However, over time, project partners (many of whom are included as co-authors of this article) found that framework of analysis-particularly with respect to 'new' commons - to be useful to understand the relationships between the globally dispersed constellation of actors who are engaged in conserving and using crop genetic resources, and to analyze their relative capacities to access, use, and improve those same resources. It also helped to understand 'social dilemmas' associated with the conservation and sustainable use of crop genetic resources that need to be addressed when thinking through institutional interventions related to the enhanced management of the crop commons.

\section{Key concepts}

Traditionally, institutional analysis concerning commons focused on resolution of social dilemmas threatening the sustainable management of common-pool resources. Common-pool resources are defined as being highly rivalrous (i.e., where one person's use of a resource detracts from its availability for use by others) and non-excludable (i.e., it is difficult or impossible to prevent access to and use of the resource). Classic examples of common-pool resources are forests, watersheds, pastures, and wild fisheries. These are resources that are 'ready-made' by nature and potentially threatened by overexploitation by unconstrained users in pursuit of selfish gains (Hardin 1968). Most of the earlier, traditional commons literature was based on case studies of limited numbers of actors involved in collective management of natural resources distributed over relatively small geographic areas (Ostrom 1990).

By contrast, the 'new' commons literature extends to consider human-made cultural products that are non-rivalrous, as well as non-excludable, and that are globally distributed and used by a potentially limitless number of people, for examples, information and software (Madison et al. 2009; Hess and Ostrom 2003). Cultural commons must encompass not only sustainable conservation and use of cultural products, but also their production (Madison et al. 2009). A social dilemma associated with cultural commons is that cultural products and cultural production are threatened by 
underuse, not unmanaged overuse, as it is the case with natural resources.

Crop genetic resources fall somewhere between natural resources and purely cultural products (de Wit 2019; Halewood et al. 2013; Dedeurwaerdere 2012). What distinguishes crops from wild plants is the historical systematic application of human selection pressures (in addition to environmental selection pressures) that contributed to the domestication, and evolution of intra-specific, genetically distinct populations of those crops. By definition, domesticated crops would not exist if they were subject to natural selection alone. One of the most persuasive descriptions of this phenomenon is found in the opening pages of Origin of Species, wherein Darwin sets the stage for readers' appreciation of natural selection, likening it to the selection pressures that farmers and, more recently, plant and animal breeders, have exerted over relatively short periods of time to create the extraordinary diversity of domesticated crops and animals, relative to the millions, billions of years of natural selection on earth (Darwin 1859). It is underuse of crop genetic resources that threatens their conservation (Padulosi et al. 2002), not overexploitation as in the case of natural resources. In the absence of continued use by humans, including being subject to farmers' and/or plant breeders' selection pressures (in addition to natural selection pressures), ancient crop wild relatives would not have been domesticated, and their extraordinary intraspecific genetic diversity would not have been realized. If human selection pressures were removed now, existing crop populations would evolve along very different trajectories: most would become extinct, either by failing to survive, or by 'reverting' to wilder forms.

In many parts of the world, at local levels, crop diversity is managed as part of a 'biocultural system', which Argumedo (2011) describes as an 'indivisible system containing the knowledge, innovations, and practices of indigenous and local communities, as they are collectively maintained. It incorporates the traditional territory itself, including natural resources and the diversity of genes, variety of crops, species, and ecosystems, and the cultural and spiritual values and laws developed within the socio-ecological context of the communities'. Such locally managed systems around the globe constitute a 'pluriverse of seed commons' (de Wit 2019); some have strong links with extra-community actors in the globally distributed commons and others have weak links, or no links at all.

For the purposes of this paper, our understanding/definition of 'agency' draws on literature concerning transformation of social-ecological systems and women's empowerment. Agency refers to the ability of individuals or social groups to make decisions about issues that are important to them. Agency depends in part upon the availability of resources concerning which choices can be made. The availability of those resources may depend on a number of factors, including material supply, and institutions that affect agents' ability to access and use them (Kabeer 1999). The exercise of agency with respect to resources leads to outcomes or achievements (Donald et al. 2017; Kabeer 1999). Agency also refers to the ability of person or group to play an active role in transforming the larger social-ecological systems in which they are embedded. Westley et al (2013) states that 'successful change agents in complex systems work to change beliefs [...] by convening all stakeholders around a common vision, change the flow of political authority and resources [...] by playing key roles in networks and mobilizing social capital, and challenge technical and legal framework [...] by encouraging integration of local knowledge, experimentation and new scientific frameworks'. In this paper, we seek to move from a structuralist conception of farmers' agency being necessarily limited as a result of recent technological developments and global-scale organizational shifts in mode of production (Buttel et al. 1990; McMichael 1994) to scenarios wherein small-scale farmers are empowered to take advantage of recent developments, to proactively engage with newly emerged actors and systems, and to make choices concerning how to exploit, and contribute to, the global crop commons.

\section{Methods}

Project activities under 'Mutually Supportive Implementation of the Nagoya Protocol and the Plant Treaty in Benin and Madagascar' (hereinafter 'Mutually Supportive project') were coordinated by national multi-stakeholder implementation committees co-convened by the Plant Treaty and the Nagoya Protocol National Focal Points in each country. ${ }^{5}$

In the earliest stages of the project, these national multistakeholder implementation committees tentatively identified two communities in each country to partner in community level piloting activities: one community in each country was selected partly on the basis that it was located in an area characterized by a genetically diverse natural resource base, and the other community was located in an area with a markedly less genetically diverse natural resource base. In Benin, the two communities were Tori-Bossito and Bonou.

\footnotetext{
${ }^{5}$ High level guidance and project monitoring for 'Mutually Supportive Implementation of the Nagoya Protocol and the Plant Treaty in Benin and Madagascar' was provided by an oversight committee including the National Focal Points for the Plant Treaty and the Nagoya Protocol for both countries, representatives of Secretariats of the Plant Treaty and of the Convention on Biological Diversity, Bioversity International and the ABS Capacity Development Initiative. Mid way through the project, Natural Justice also joined the oversight committee.
} 
In Madagascar, the two communities comprised a group of farmers in the rural municipality of Analavory, Itasy Region, and a group of villages managing the forest of Iaroka Antavolobe,located in Alaotra Mangoro Region.

Members of the national multi-stakeholder implementation committees visited the communities, explained the project rationale and modus operandi, and the resources that would be made available to support local engagement. On the basis of these interactions, community representatives confirmed willingness to participate. As a first step, they identified local organizations to join the national multistakeholder implementation committee to help in overall management of the project and to act as a liasons between the implementation committees and the communities. The community organizations selected varied considerably; they included the municipal governments, a customary leader, a women's agricultural production group, and a local community youth organization. ${ }^{6}$ Most of the community-level work in both countries was facilitated by a civil society organization, Natural Justice, working closely with the leading community organizations.

Over the course of its first year, the project supported a number of facilitated, open community meetings to discuss (i) possible ways in which the communities could take advantage of their national government's commitment to implement the Nagoya Protocol and the Plant Treaty and (ii) activities the project could support to help communities advance those interests. The Plant Treaty and Nagoya Protocol National Focal Points attended those meetings; and they underscored that the community level work could inform the national level policies that were being developed at the same time.

The project provided financial and technical support for the communities and other national partners to follow up, over the course of the successive 2 years, on the portfolio of activities that the communities agreed to be most relevant. On occasion, scientists and policy experts from outside the country, from FAO, Natural Justice, ABS Capacity Development Initiative, and the Alliance of Bioversity International and CIAT participated in these activities to provide training to use relevant tools and methods as described below.

Community engagement in developing the biocultural community protocols followed methods set out in the

\footnotetext{
${ }^{6}$ In Benin, the lead organizations are local biodiversity management committees: the 'Comité de gestion des forêts sacrées de Bonou' (13 members), and a newly established committee ( 8 members) in ToriBossito, which is supported by Jeunesse Sans Frontières (NGO active in agricultural production and medicinal plants). The lead organizations in the communities of Madagascar are 'VOI Firaisan-Kina', a local community-based organization dealing with forest management, in Antavolobe, and 'Santatra', a local farmer seed group, in Analavory.
}

publication entitled Biocultural Community Protocols: A Toolkit for Community Facilitators, published by Natural Justice (Shrumm and Jonas 2012). Each community followed slightly different processes, but they included many the following common elements, starting with large community meetings wherein the concept of biocultural community protocols was introduced. Participants discussed the potential benefits and limitations of the protocols, and the commitments needed from the community to develop and use them. Separate meetings for men and women participants were held to capture the needs and opinions of each group on the process. The subsequent steps to follow for developing the protocols were determined by these larger community meetings. In Bonou, for example, a community assembly of approximately 200 people participating in an initial meeting created six thematic working groups to consider: (i) the identity of the community, (ii) the natural resource base, (iii) sociocultural resources, (iv) political and institutional factors, (v) legal issues, and (vi) economic issues. Those inputs were fed into a smaller committee that developed the text of the biocultural community protocol. At the end of the process, the same larger community assembly considered and approved the protocol. The other three communities also created small committees to take the development of the protocols forward. As part of the process, they organized additional, smaller community consultation meetings to gather information, perspectives and share progress. They organized 'role play' exercises to analyze how to build on local institutions for decision-making. Part way through these processes, when the communities decided that the protocols should also address the means by which they could exercise their rights to access crop genetic resources from other places, interactions with representatives of national agricultural research organizations were arranged to learn about norms governing the introduction of genetic resources into the country from foreign sources. Inter-generational discussions between elders and young people in the communities were included as part of the consultation processes. Municipal authorities were consulted in the latter stages of the development of the protocols. The protocols were ultimately adopted through large community meetings and subsequently adopted by relevant municipal authorities. Considered across the four communities, on average, each biocultural community protocol processes involved 4 meetings with a total of 950 participants, $28 \%$ of whom were women.

At the same time, the national multi-stakeholder implementation committees supported a process to develop draft national laws (in the form of Executive Orders) implementing both the Nagoya Protocol and the Plant Treaty; these drafts were eventually adopted by the end of the project by the Council of Ministers in both countries. In this paper, we focus only on those activities and aspects of the adopted 
laws that are directly relevant to the recognition/promotion of community rights.

\section{Findings}

\section{Community interests in implementation of the international agreements}

The initial level of awareness among community participants concerning the Nagoya Protocol and the Plant Treaty was extremely low. No participants appeared to be familiar with the Plant Treaty's Multilateral System of Access and Benefit-sharing (Multilateral System) or with the internationally linked system of crop genetic resources collections from which materials can be accessed for free through the Multilateral System. No community members or community organizations had ever accessed crop genetic resources through the Multilateral System under the standard material transfer agreement (SMTA), used for all transfers of materials under the Multilateral System. Their main sources of seed were/are neighbors, government extension agents and small agro-dealers. No one in the communities had entered into legal agreements to provide access to genetic resources collected from their lands, although some organizations from outside the communities had expressed interest in recent years in accessing forest genetic resources and related traditional knowledge.

After the initial round of awareness-raising workshops, community members agreed that they should seek to take advantage of the opportunities created by their respective national government's ratification of both the Nagoya Protocol and the Plant Treaty to promote their collective community interests in: (a) being recognized as managers/stewards of local biological diversity, (b) controlling outsiders' access to local biological resources and associated local traditional knowledge, and (c) accessing crop genetic resources from other places in the world to experiment with and introduce them into their local agricultural production systems.

\section{Community-prioritized activities to build capacity (and profile) as biodiversity managers in the context of national implementation}

The project partners identified a range of activities to build the communities' collective capacity to pursue these interests, building on local institutions and knowledge. First, they embarked on exercises to identify the diversity of biological resources managed across the community. This was recognized as fundamental to increasing their capacity as diversity managers, their ability to control others' access, and to identify crop genetic resources they do not have and could possibly access from elsewhere. Given limited resources, project partners decided to focus first on documenting the inter- and intra-specific diversity of plants that farmers were managing on farm. They did so using a combination of tools including transect walks, whereby they identified and documented crops distributed along mapped walks across farmers' and public lands in the community, and participatory 'four cell' analyses, whereby groups of farmers identified the richness and evenness of the distribution of crop varieties across their communities (Sthapit et al. 2012; Vernooy et al. 2019). They also adopted processes for recording the crop diversity present in their communities, employing written crop diversity registries, which are maintained by organizations as agreed during the community consultations. ${ }^{7}$

To promote the recognition of their interest/right to regulate access to biological resources and traditional knowledge, each community documented the distribution of decision-making powers concerning the management of genetic resources across the community (including customary and formal government-sanctioned authorities) and worked-through consultation processes to forge common agreement between community members on processes that should be followed when someone from outside the community expresses an interest in accessing genetic materials from within the community, taking into consideration that different people will need to be consulted with respect to different resources in different locations. It was in this context, initially, that the communities decided to develop biocultural community protocols as local level policy instruments to be endorsed by local authorities to assert their collective right to regulate access to resources in its territory, and to establish the relevant authorities and processes to follow depending on the resources in question.

To identify outstanding needs for crop genetic resources from elsewhere, in addition to registering plants managed by farmers and the four square analyses of richness and

\footnotetext{
7 In Tori-Bossito, project partners adopted two registries: one for crop genetic resources and another for species of local plants from sacred forests and private plantations, botanical gardens. The VicePresident and the Secretary of the Biodiversity Registry Management Committee are responsible for the management of the registry, which is kept at the Town Hall. In Bonou, the President and the Secretary of the Biodiversity Management Committee are responsible for the management of the registry, which is kept at the royal palace. In both localities, the entire local community has free access to the registries, but access by people from outside of the community is left to the discretion of the managers. In Analavory, Madagascar, the biodiversity registry includes crop genetic resources (primarily rice, maize and beans) and associated traditional knowledge existing within the boundaries of the rural Municipality, as well as resources conserved in institutions such as FOFIFA, FIFAMANOR, and other NGOs. The president of the FAMA Cooperative, together with the Biodiversity Management Committee, keeps the registry and is also responsible for its data management. The Antavolobe biodiversity registry includes crop genetic resources. A separate person from the community takes responsibility for updating the registry for each crop.
} 
evenness, community members worked through participatory exercises to identify the impacts of recent climate changes on key food security crops, and to identify traits that would be necessary for a new variety (or new species) to grow better under existing conditions. These exercises were facilitated by experts in conducting community vulnerability analyses and supported by experts in agronomy, plant breeding and in crop genetic resources conservation drawn from both national and international agricultural research organizations. Thereafter, community members (and other project partners recommended by the national multi-stakeholder implementation committees) were provided training on how to use existing publicly available crop genetic resources databases (i.e. national genebank data bases and Genesys ${ }^{8}$ ), and publicly available data on existing and predicted climates in local areas (Worldclim ${ }^{9}$ ) to identify germplasm conserved in collections around the world that is potentially adapted to present and future climates in the communities concerned, and that is freely available under the Plant Treaty's Multilateral System (Otieno et al. 2018; Gloria 2018; Bedmar Villanueva et al. 2017; Halewood et al. 2017). Exchange visits were organized between the two communities within each country to share information about crop varieties that performed well under changing climates.

Based on all of the above information, research teams (including community members, and scientists from agricultural research organizations) agreed upon combinations of materials that they would seek to obtain from various sources, including from other communities participating in the project, from national agricultural research organizations, and from genebanks around the world. They sought materials that were once used by the communities but had been lost, materials that performed well in other communities under climatic circumstances similar to their own, and materials that were identified through the climate adaptation modeling work described above, or that were recommended by genebank managers or plant breeders taking the communities' preferences into consideration once the requests were made.

Community representatives were assisted by project partners (NGOs, agricultural research organizations, national genebanks, extension agencies) to formally make requests for the identified materials to genebanks in other countries. In some cases, the community was joined in making the requests by the local municipal government or the national agricultural research organization to increase the likelihood of the request being favorably considered by the provider and to expedite the necessary test of the materials pursuant to national phytosanitary regulations. In some cases,

\footnotetext{
${ }^{8}$ Genesys url: https://www.genesys-pgr.org/.

9 Worldclim url: https://worldclim.org/.
}

community leaders agreed that an organization from outside the community (i.e., a university and a national agricultural research organization) should take receipt of the materials first after release from quarantine, and to multiply the seeds received, before passing them on to the farmers.

Once sufficient seed was multiplied for experimentation, it was distributed among the community members for testing, following a number of different methods that were mutually agreed between community members and project partners. Seed was distributed for growing/testing on both communal lands and on farmers' individual holdings. Criteria for managing the plants were agreed, as were the methods for recording observations of their performance, and for pooling and comparing those observations within the community.

The Mutually Supportive project lasted for 3 years; so the project ended after just one season of community experimentation with the crop genetic resources that farmers received. Since then, farmers in some of the communities have engaged in participatory plant variety selection to enhance the more promising materials that they received, multiplied, and tested. In Madagascar, they have engaged in partnerships with plant breeders from the national agricultural research organization to conduct participatory plant breeding. In both Benin and Madagascar, the communities secured additional resources to develop community seed banks, to help them conserve and make available adequate supplies of the seed of genetic resources/varieties they had received and enhanced, and of local varieties.

\section{Biocultural community protocols to promote/codify community access to crop genetic resources (in addition to regulating access to resources managed by the community)}

In retrospect, the combined activities, tools and methods described above, and the partnerships struck between the communities and NGOs, genebanks, universities, and national agricultural research organizations seem straightforward and relatively obvious. They did not at the time. Each step along the way, each challenge, and each strategy for overcoming those challenges-including reaching out to and enlisting assistance of organizations from outside the communities-required protracted interaction between all the partners involved in the project, from local to international levels. It also required considerable dedication of resources to foster common understanding among community members of the decisions to be made, by whom, and upon what criteria, based on local institutions (or adaptations of those institutions). Based on these experiences, it was decided that it would be useful to expand the scope of the biocultural community protocols to codify/promote the communities' collective interests in accessing crop genetic resources from 
elsewhere. In particular, the protocols address the communities' collective interests to:

- define themselves as communities, including their relationship with the local natural resources base, and the principles that inform how they manage their resources;

- periodically assess the state of crop genetic diversity managed by the community, including through the maintenance of community biodiversity registries. (The protocols also identify the organization responsible for maintaining the registry in each community);

- periodically engage in exercises to identify crop genetic resources that the community needs to obtain from sources outside the community. (The level of detail varies across the protocols in terms of describing possible tools and methods to be used, and utility of engaging extra-community organizations in those exercises);

- proactively engage with organizations from outside the communities (e.g., NGOs, national agricultural research organizations, national genebanks) to provide partnership/ technical assistance to identify and request crop genetic resources that are available from genebanks, breeders and other sources from within the country and around the world;

- establish their own relationships with national phytosanitary authorities, and/or proactively engage with other organizations that can act as 'go betweens' with those authorities to assist in getting materials requested from other countries tested and released for use in a timely fashion;

- develop strategies for multiplying seeds or other reproductive materials coming from outside, evaluating their performance, and sharing related information;

- develop strategies for storing adequate supplies of seed of locally useful varieties that are not available through other means;

- develop strategies for enhancing varieties through selection or participatory plant breeding;

- provide guidance for how to respond to requests from farmers and organizations from outside the communities that are interested in accessing, using and possibly commercializing crop varieties/diversity managed by the community (This penultimate bullet point is actually taken up in other parts of the protocol, dealing with communities' collective interest in controlling access to genetic resources by people and organizations from outside the community), and

- assert and call for the recognition of their rights and interests as set out in the bullet points above, as required by the Plant Treaty and the Nagoya Protocol.

\section{Discussion}

\section{Regarding mutually supportive implementation of the Plant Treaty and the Nagoya Protocol}

The objectives of the Convention on Biological Diversity (CBD) and of the Plant Treaty are identical: conservation and sustainable use of genetic resources and equitable sharing of benefits derived from their use. However, the access and benefit-sharing systems created/promoted by the CBD and its Nagoya Protocol on one hand, and the Plant Treaty on the other, are very different. The CBD and its Nagoya Protocol generally promote bilateral access and benefit-sharing regulation and deal making with providers and recipients agreeing between themselves on de novo access and benefit-sharing terms and conditions, subject to approval by a competent national authority. The Plant Treaty, in contrast, creates a Multilateral System, whereby all Contracting Parties agree to virtually pool specified crop genetic resources and exchange them using a SMTA with fixed benefit-sharing terms (Manzella 2013). National access and benefit-sharing systems implementing the CBD/Nagoya Protocol and the Plant Treaty are necessarily closely intertwined. Without coordinated, mutually supportive implementation measures at the national level, stakeholders are confused by which rules apply, and public authorities charged with the administration of these systems often lack confidence to make decisions given uncertainties about the relationships between the two access and benefit-sharing systems. It is partly for these reasons that the Conference of the Parties of the CBD and its Nagoya Protocol and the Governing Body of the Plant Treaty have both repeatedly called on Contracting Parties and stakeholders to work on developing models for implementation of both agreements in mutually supportive ways.

The Nagoya Protocol (Article 12.1) states that 'in accordance with domestic law' Contracting Parties shall 'take into consideration indigenous and local communities' customary laws, community protocols and procedures, as applicable', when setting up procedures to regulate access to traditional knowledge associated with genetic resources. Furthermore, Article 12.3 calls for Parties to support the development of community protocols, and Article 12.4 protects customary use and exchange of genetic resources and associated traditional knowledge within and among indigenous peoples and local communities. The Plant Treaty does not mention community protocols per se, but it does commit Contracting Parties, subject to their national laws, to promote farmers' rights to 'equitably participate in sharing benefits arising from the utilization of plant genetic resources for food and agriculture' and to 'protect traditional knowledge relevant to plant genetic resources for food and agriculture' (Article 9). Both instruments recognize the contributions of farmers/ 
indigenous peoples and local communities to in situ/on farm management and promote their engagement in participatory research and development related to conservation and use of genetic resources.

The biocultural community protocols developed in the Mutually Supportive project are meant in part to take advantage of countries' commitments under these agreements and other related international instruments ${ }^{10}$. That said, they are considerably broader in scope than what is anticipated in the Nagoya Protocol, setting standards for access to genetic resources managed by the communities, including crop genetic resources (in addition to traditional knowledge associated with those resources) and best practices for communities to practically implement their right to access crop genetic resources under the Plant Treaty's Multilateral System. While there have been a number of projects and studies analyzing options for implementing the Nagoya Protocol and the Plant Treaty at the level of national policies and law (Joint Capacity Building Programme 2017, 2018; Halewood et al. 2013), as far as the authors are aware, there are no studies explicitly analyzing mechanisms-like these biocultural community protocols-for mutually supportive implementation of the two international instruments at local levels.

\section{Regarding shifting modes of production and conservation of crop genetic diversity}

The portfolio of measures adopted by the communities, including the biocultural community protocols, are best understood when considered in the context of the extraordinary shifts in the modes of production, conservation and use of crop genetic diversity over the course of the last 50 years.

Since the dawn of agriculture, small-scale farmers were the main producers of domesticated crops and crop genetic diversity, exchanging crop genetic resources through 'informal' networks, and subjecting those resources to combined human and environmental selection pressures in different locations around the world (Vigouroux et al. 2011). Access to and use of crop genetic diversity was critically important

\footnotetext{
10 The Convention on Biological Diversity, Article 8(j), encourages protection of traditional knowledge of indigenous peoples and local communities linked to in situ conservation. The 2nd Global Plan of Action on Plant Genetic Resources for Food and Agriculture (cross referenced in Article 5 of the Plant Treaty) identifies on farm management and crop improvement as priority activities. The UN Declaration on the Rights of Indigenous Peoples, referenced in the Nagoya Protocol's preamble, establishes the principle of free, prior and informed consent whenever indigenous peoples' land, resources, knowledge or cultural artefacts are accessed and/or used; The UN Declaration on the Rights of Peasants and Other People Working in Rural Areas (Article 19) reaffirms rural people's rights to seeds and related traditional knowledge, calling for States to protect these rights and support peasant seed systems.
}

for farmers, as it was the means by which they were able to develop crops that were suited to their local conditions (Almekinders et al. 1994; Elias et al. 2000; Mercer and Perales 2010), adapting and conserving them through use (Bellon and Brush 1994; Brush 1995; Bezançon et al. 2009). In the absence of continued production and conservationthrough-use, farmers' crop varieties, and the genetic diversity they represent, would disappear. European colonialism and imperialism accelerated the spread of crops around the world (Mann 2011; Diamond 1999), increasing international interdependence on crop genetic resources.

Since the rediscovery of Mendelian genetics, the mode of production of new crop varieties has changed dramatically. Public and private research and development organizations have largely taken over the business of plant breeding. National and regional governments regulate seed quality and trade. New crop varieties and quality seed have contributed enormous benefits to farmers and national economies worldwide. It is beyond the scope of this paper to provide an overview of those benefits, or even of the extensive literature that documents the contributions of plant breeding (Asfaw et al. 2012; Kassie et al. 2010; Varshney et al. 2019).

Over the course of the last 50 years, a radically new constellation of organizations and institutional arrangements has evolved to support the long-term conservation of crop genetic diversity. For example, the International Board on Plant Genetic Resources for Food and Agriculture (IBPGR), hosted by the UN FAO, was created in 1974 to coordinate the collection of farmers' varieties that were being replaced (or were at risk of being replaced) by the widespread adoption of 'green revolution' crop varieties. Between 1975 and 1995, IBPGR coordinated collection of over 200,000 samples from over 136 countries and organized their conservation in genebanks around the world (Thormann et al. 2019). There has been a boom in establishment of national and regional genebanks world-wide. The Second Report on the State of the World's Plant Genetic Resources for Food and Agriculture (FAO 2010) states that by 2010, there were approximately 7.4 million accessions in 1750 genebanks. The Svalbard Global Seed Vault sits at the apex of this system, providing an ultimate safety back up of approximately 1 million crop accessions deposited by organizations from around the world, with a capacity to host another 3 million accessions. Much of the world's historical crop genetic diversity is now concentrated and stored in those collections (Scarascia-Mugnozza et al. 2002; Fowler and Hodgkin 2004). At an international level, the UN FAO's Global System of Conservation and Use of Plant Genetic Resources for Food and Agriculture was designed to promote coordination among the organizations around the world hosting these crop and forage collections (Scarascia-Mugnozza et al. 2002; Hodgkin et al. 2013). In 2004, under the auspices of the UN FAO, the international community adopted the Plant 
Treaty, which creates the Multilateral System, which establishes rules for exchanging crop and forage genetic resources for use in food and agriculture research, including plant breeding. As of July 2020, 146 countries have ratified the Plant Treaty, and CGIAR Centers (and other international institutions hosting ex situ collections) have signed agreements pledging to make their collections available under the terms of the Plant Treaty.

Most farmers in developed countries source most of their seed from seed companies, returning each year to buy seed of hybrid or genetically modified varieties. Since they no longer save, sow, and select seeds from year to year, they are no longer directly engaged in the development and conservation of crop diversity through use. This is also a trend in some developing countries, in areas where markets for commercial hybrid varieties are opening up.

On the other hand, in many parts of the world, smallscale farmers continue to actively harvest, select, save, plant their own seeds (or other planting materials) of a range of crops, subjecting them to farmer selection pressures to influence the evolution. Those same farmers provide and obtain seeds through 'informal' seed systems, contributing to their dissemination and exposure to selection pressures in other agro-ecosystems. It is estimated that farmers in developing countries continue to access up to $80 \%$ of their seed through 'informal' seed systems (Cooper 1993; Sperling and McGuire 2010; McGuire and Sperling 2016; World Benchmarking Alliance 2019) and continue to manage a wide diversity of materials (both inter- and intra-specific diversity) as part of their production and risk management strategies (Altieri 2008). Despite their importance in many parts of the world, where they continue to play an important role for food security, farmers' 'informal' seed exchange networks are also being negatively affected by a number of factors, including farmers' migrating to cities, agrobiodiversity loss, urban encroachment on agricultural lands (Hazell 2005, 2007) and restrictive seed laws (Louwaars 2007). Small-scale farmers in developing countries complain that they do not have access to quality seed (Bishaw et al. 2013); and that they would welcome access to more crop diversity with which they could experiment and introduce into their production systems (Vernooy et al. 2019; Bishaw et al. 2010; Jones et al. 2001).

\section{Increasing farmers access to and use of crop diversity}

One means of enhancing small-scale farmers' agency in the evolving global crop commons-without simply trying to reconstruct things 'the way they were before'-is to ensure that they are able to benefit from the new technological and organizational innovations that characterize the crop commons, and to raise the profile of what they contribute to the global commons through use of their specialized skills and resources, and strengthening their network ties with other actors in the commons.

One point of entry in this regard is strengthening farmers' access to, and use of, crop diversity in ex situ collections. There is currently a broader range of genetically diverse planting materials that is potentially available to farmers in ex situ collections around the world than farmers ever could have dreamed of accessing in the past via informal exchange networks. Furthermore, those materials are generally in good health, and they are available, or at least should be available, to farmers for free (or minimal administrative costs) under the Plant Treaty's Multilateral System. However, experience has shown that farmers (including both large-scale industrial farmers and small-scale farmers) are not accessing crop diversity from those collections. For example, only $1-4 \%$ of the materials transferred each year from CGIAR genebanks and breeding programs via the Multilateral System sharing has been accessed directly by farmers around the world (Westengen et al. 2018; CGIAR 2019). ${ }^{11}$

As highlighted in the findings section above, farmers' ability to take advantage of, and contribute to, the global system will depend, at least in part, on striking up mutually advantageous partnerships with 'formal sector' organizations that can assist farmers to 'interface' with the global system, and work together to generate value for both farmers and the global system as a whole (in the form of improved and conserved genetic resources and knowledge). Like the farmers in Benin and Madagascar, most small-scale farmers most likely are not aware of the Plant Treaty's Multilateral System and their legal right to access crop genetic resources from around the world through that system for free. Similarly, most small-scale farmers around the world are not in a position, on their own, to be able to identify which particular materials out of the approximately 2,300,000 million accessions as of June 2020 in the Multilateral System ${ }^{12}$ are potentially useful to them, for example, following the methods piloted by the multi-stakeholder teams in Benin and Madagascar combining farmer needs assessments with passport and climate data to identify materials that are adapted to changing local climate conditions (Otieno et al. 2018). Complicating matters still further, some providers of materials

\footnotetext{
11 By contrast, those collections are accessed and used primarily by national agricultural research organizations, universities, genebanks and seed companies (Galluzzi et al. 2016; López Noriega et al. 2019). Of course, CGIAR materials distributed to national agricultural research organizations are often used to develop and release new varieties, which then are made available to farmers. Farmers in areas that have access to an adequate supply of seed of such varieties may feel their needs for diverse materials are satisfied. Statistics on direct distribution to farmers from CGIAR collections need to be considered in this larger context.

12 https://mls.planttreaty.org/itt/index.php?r=stats/pubStats.
} 
under the Multilateral System do not consider direct requests from farmers in their own countries, or requests that originate from outside their countries if they do not come through public agencies, or larger private organizations (Joint Capacity Building Programme 2018), despite the fact that natural and legal persons are supposed to enjoy facilitated access through the Multilateral System. Similarly, national phytosanitary control systems in some countries may also delay or decline to process materials being imported by small farmers (and/or other unknown importers) when required to allocate scarce resources, choosing instead to test materials first that are being imported by national agricultural research organizations, companies, and large NGOs, particularly those bound for commercial use. The result can be that materials actually die before they are tested and released from quarantine for use by the farmers concerned. Partnering with, or operating through the legal personality of, larger organizations is one strategy that farming communities can employ to address these challenges.

In most cases, however, accessing materials will only represent the beginning of research and development activities where, again, communities can benefit from partnerships with 'outside agencies' and epistemological communities to combine the farmers' own know-how and expertise (and in some cases, genetic materials) with those of formal sector research and development organizations. Participatory (Ceccarelli 2015; Ceccarelli and Grando 2007) and evolutionary (Döring et al. 2011) plant breeding are classic examples of such hybridized activities designed to mix and benefit from farmers' and formal sector plant breeders' knowledge, perspectives and values. Newly developed approaches to engage farmers as citizen scientists in large-scale variety evaluation projects represent another means by which farmers and public and private research and development organizations can work together to add value to a broad diversity of crop genetic resources, including those in national and international genebanks (van Etten et al. 2019; Beza et al. 2017). Community-based agrobiodiversity management projects also provide a context in which farmers are often interested in receiving materials from genebanks (including restored materials) to be introduced into, and managed as part of, local production systems, subject to conservation through use (and intergenerational selection) by farmers, thereby straddling the ex situ and in situ divide. Westengen et al. (2018) provide a useful overview of these and other situations-including emergency seed relief (which is not mentioned here) - in which farmers access materials directly from genebanks. The biocultural community protocols adopted in Benin and Madagascar highlight the need for community consultations, and engagement with extracommunity organizations, to develop such partnerships.

By way of corollary, farmers can provide access to farmerimproved materials to users outside their communities, and share information about the performance, in their local settings, of materials they access from genebanks or plant breeders. Of course, this kind of access and information sharing needs to be subject to terms that are approved by the farmers. The biocultural community protocols address the possibility that communities may decide to make crop genetic resources available using the Plant Treaty's SMTA or subject to other terms and conditions deemed fit pursuant to the decision making processes and authority set out in the protocols. They do not specifically address the possibility of the communities sharing information with providers about the performance of materials they have received; this, we believe, was an oversight, given farmers' participatory evaluation of both crop genetic resources (including both the products of formal breeding programs and genebank materials) is an established form of farmer-formal sector partnership as described above. Genebank managers and breeders value such information highly; it is key to adding value to collections (helping others know the potential utility of conserved materials) and for breeders to know if/how to adjust their breeding research and development. Breeders and genebank managers frequently complain that they do not get such information back once they distribute materials (FAO 2010; CGIAR 2019). By systematically providing performance data back to providers, the communities would be helping to close a virtual loop in material and information flows, and add value to the crop commons overall. This is not a new concept; under the SMTA, recipients undertake to share non-confidential research data linked to the received materials through the Plant Treaty's Global Information System (GLIS). The fact is, however, that most recipients are not getting back to providers or the GLIS with such information, with the result that opportunities to enhance the value of the Multilateral System are lost. In the future, we would recommend that such protocols also promote community level strategizing and decision-making about sharing performance data back to the providers from whom they access the materials concerned and to the GLIS (or alternatively, making a collective decision to keep such information confidential). This decision should come from the community themselves after clearly understanding such process, following the principles enshrined in the development of these tools.

\section{Regarding the biocultural community protocols and farmers' collective action interests}

There is no one fixed model for biocultural community protocols. They are developed differently depending upon their objectives, the agroecosystems and socio-political cultures of the communities and the country concerned (SCBD 2019). For the most part, they have focused on enhancing communities' management of natural resources (Bavikatte and Jonas 2009; Jukic and Collings 2013) and 
biological diversity in particular (Lassen et al. 2018). One common objective of biocultural community protocols is to affirm the status and rights of the communities concerned to manage resources within their territories of life. A closely related objective of many of the biocultural community protocols developed to date is to strengthen the ability of communities to control outsiders' access to genetic resources and associated traditional knowledge managed by community members (Shrumm and Jonas 2012; Jonas et al. 2010; Delgado 2016). These protocols were inspired largely by the CBD, 1993, and more recently, by its Nagoya Protocol. Subject to some notable exceptions (Argumedo 2011; LPP 2018) these protocols have tended to focus on natural resources, wild endemic flora and fauna and traditional knowledge associated to these resources, and less on agricultural biological diversity.

The biocultural community protocols described in this article include the two core elements described above. In addition, they promote small-scale farmers' access to crop genetic resources, taking advantage of both countries' ratification of the Plant Treaty.

The biocultural community protocols promote farmers' collective actions in this respect for a number of interrelated reasons. As highlighted above, small-scale farmers' contributions to domestication, crop diversity generation and conservation were largely collective, and intergenerational in nature. Small-scale farmers in most of the world continue to exchange seeds with neighbors within their community (Samberg et al. 2013; Coomes et al. 2015). Not all farmers within a community will use (and conserve through use) all varieties every year; instead, the overall portfolio of crops and varieties at the community level is larger than that which each farmer keeps individually. Nonetheless, from year to year, what each farmer chooses to grow, as will the combination of seeds that the farmer will access from her neighbors, the local market, and other sources will change. So, when considering what diversity exists, and is available to farmers-prior to considering accessing diversity from the 'global system'-it makes sense to measure the distribution and richness of crop diversity at the collective, community level (Jarvis et al. 2011) and what would be available commercially or though extension services. By extension, it is logical that interests in accessing crop genetic resources from sources outside the community are collective interests shared by all farmers in the community. The fact that crop genetic resources accessed from genebanks around the world come in very small quantities underscores the need for coordinated action by farmers within the community (often in coordination with other extra community organizations) in the management of those resources once they are received, to ensure that they are multiplied, experimented with, and conserved in ways that are useful to the community as a whole.

\section{Conclusion}

By addressing farming communities' collective interests in gaining access to crop genetic resources, and managing and improving them, the biocultural community protocols described in this article respond to the social dilemma associated with the crop commons: that underuse, not overuse, threatens the sustainable management of crop genetic diversity. Even if they are not a panacea, biocultural community protocols help communities to proactively respond to the fact that can and should continue to play active roles in the generation and conservation of crop diversity (and addition of value to those resources through research). The process of developing such protocols, if carried out in an inclusive and participatory manner, can raise the awareness of farming communities of their collective interests and rights under the Nagoya Protocol and the Plant Treaty. Biocultural community protocols can provide roadmaps for how communities can pursue those interests and rights in practical ways; they can help strengthen farming communities' institutions for collective crop diversity management and their capacities to take advantage of the technological and organizational developments that have changed the shape and functioning of the global crop commons over recent decades. They set the scene for communities to be able to engage in proactive, equitable partnerships with genebanks, plant breeders, extension agencies and other organizations to enhance the benefits that they can derive from, and contribute to, the crop commons. As such, biocultural community protocols are a way of reconnecting the different layers of governance of the internationally distributed crop commons, from local to global levels, while specifically strengthening the position within that system of farming communities as biodiversity managers.

Of course, the biocultural community protocols on their own will not create new partnerships if the other actors in the crop commons-among them breeders, genebank managers, regulatory authorities-choose not to engage. That said, the protocols send a clear message to those actors that the communities are organized and ready to engage in creative partnerships, and they highlight the means by which the communities can add value to joint enterprises. Clearly articulated biocultural community protocols should also help dispel research and development partners' concerns about transaction costs related to uncertainty about how to initiate contact with the communities concerned and negotiate partnership agreements. The potential impact of the protocols in this context was significantly increased by being recognized in national decrees implementing the Nagoya Protocol and 
the Plant Treaty in Benin and Madagascar, as this recognition creates additional incentives for research and development and regulatory agencies to respond positively and proactively engage with communities in ways described in the protocols.

The biocultural community protocols presented in this paper were developed in part to help the communities take advantage of their national governments' ratification of the Plant Treaty and the Nagoya Protocol, to reconfigure relationships and the flow of resources and knowledge within the crop commons. Other recently adopted international instruments (e.g., the UN Declaration on the Rights of Indigenous Peoples, and the Declaration on the Rights of Peasants and Other People Working in Rural Areas) and others that are likely to be adopted in the next year (e.g. Post 2020 Global Biodiversity Framework and the UN FAO Global Plan of Action for Agrobiodiversity) will provide more opportunities to promote the agency of farmers, indigenous people and local communities as managers of biological resources and socioecological systems. We very much hope that donor organizations will support communities to develop biocultural community protocols, and encourage research, development and regulatory agencies to partner with communities in conformance with those protocols.

Open Access This article is licensed under a Creative Commons Attribution 4.0 International License, which permits use, sharing, adaptation, distribution and reproduction in any medium or format, as long as you give appropriate credit to the original author(s) and the source, provide a link to the Creative Commons licence, and indicate if changes were made. The images or other third party material in this article are included in the article's Creative Commons licence, unless indicated otherwise in a credit line to the material. If material is not included in the article's Creative Commons licence and your intended use is not permitted by statutory regulation or exceeds the permitted use, you will need to obtain permission directly from the copyright holder. To view a copy of this licence, visit http://creativecommons.org/licenses/by/4.0/.

\section{References}

Almekinders, Connie J.M., Niels P. Louwaars, and G.H. De Bruijn. 1994. Local seed systems and their importance for an improved seed supply in developing countries. Euphytica 78 (3): 207-216.

Altieri, Miguel A. 2008. Small farms as a planetary ecological asset: Five key reasons why we should support the revitalisation of small farms in the global south. Penang, Malaysia: Third World Network

Altieri, Miguel A., Clara I. Nicholls, Alejandro Henao, and Marcos A. Lana. 2015. Agroecology and the design of climate changeresilient farming systems. Agronomy for Sustainable Development 35 (3): 869-890.

Argumedo, Alejandro. 2011. Community biocultural protocols: Building mechanisms for access and benefit sharing among the communities of the Potato Park based on Quechua customary norms (summary report). International Institute for Environment and Development. http://pubs. iied. org G, 3168.
Asfaw, Solomon, Menale Kassie, Franklin Simtowe, and Leslie Lipper. 2012. Poverty reduction effects of agricultural technology adoption: A micro-evidence from rural Tanzania. Journal of Development Studies 48 (9): 1288-1305.

Bavikatte, Kabir, and Harry Jonas. 2009. Bio-cultural community protocols: a community approach to ensuring the integrity of environmental law and policy. Square Brackets - Issue 2, November 2009, CBD, Bonn, Germany.

Bedmar Villanueva, Ana, Isabel López Noriega, Michael Halewood, Gloria Otieno, and Ronnie Vernooy. 2017. Using access and benefit sharing policies to support climate change adaptation. Abingdon: Routledge.

Bellon, Mauricio R., and Stephen B. Brush. 1994. Keepers of maize in Chiapas, Mexico. Economic Botany 48 (2): 196-209.

Beza, Eskender, Jonathan Steinke, Jacob Van Etten, Pytrik Reidsma, Carlo Fadda, Sarika Mittra, Prem Mathur, and Lammert Kooistra. 2017. What are the prospects for citizen science in agriculture? Evidence from three continents on motivation and mobile telephone use of resource-poor farmers. PLoS ONE 12 (5): e0175700.

Bezançon, Gilles, Jean-Louis Pham, Monique Deu, Yves Vigouroux, Fabrice Sagnard, Cédric Mariac, Issoufou Kapran, Aïssata Mamadou, Bruno Gérard, and Jupiter Ndjeunga. 2009. Changes in the diversity and geographic distribution of cultivated millet (Pennisetum glaucum (L.) R. Br.) and sorghum (Sorghum bicolor (L.) Moench) varieties in Niger between 1976 and 2003. Genetic Resources and Crop Evolution 56 (2): 223-236.

Bishaw, Zewdie, P.C. Struik, and A.J.G. Van Gastel. 2010. Wheat seed system in Ethiopia: Farmers' varietal perception, seed sources, and seed management. Journal of New Seeds 11 (4): 281-327.

Bishaw, Zewdie, P.C. Struik, and A.J.G. Van Gastel. 2013. Farmer's seed sources and seed quality: 2 . Seed health. International Journal of Plant. Production 7 (4): 637-657.

Brush, Stephen B. 1995. In situ conservation of landraces in centers of crop diversity. Crop science 35 (2): 346-354.

Brush, Stephen B. 2000. Genes in the field: on-farm conservation of crop diversity. Ottawa: IDRC.

Buttel, Frederick H., Olaf F. Larson, and Gilbert W. Gillespie Jr. 1990. The sociology of agriculture. Santa Barbara: Greenwood Press Inc.

Ceccarelli, Salvatore. 2015. Efficiency of plant breeding. Crop Science 55 (1): 87-97.

Ceccarelli, Salvatore, and Stefania Grando. 2007. Decentralized-participatory plant breeding: An example of demand driven research. Euphytica 155 (3): 349-360.

CGIAR. 2019. Report by the eleven CGIAR Centers that signed agreements under article 15 of the treaty. report on cooperation with other international bodies and organizations. "Eighth session of the governing body of the international treaty on plant genetic resources for food and agriculture". Rome, November 2019. https ://www.fao.org/3/na897en/na897en.pdf. Accessed July 10, 2020.

Coomes, Oliver T., Shawn J. McGuire, Eric Garine, Sophie Caillon, Doyle McKey, Elise Demeulenaere, Devra Jarvis, Guntra Aistara, Adeline Barnaud, and Pascal Clouvel. 2015. Farmer seed networks make a limited contribution to agriculture? Four common misconceptions. Food Policy 56: 41-50.

Cooper, David. 1993. Plant genetic diversity and small farmers: Issues and options for IFAD. Rome: International Fund for Agricultural Development.

Darwin, Charles. 1859. On the origin of species by means of natural selection. London: Murray.

de Boef, Walter, Abishkar Subedi Simon, Nivaldo Peroni, Marja Thijssen, and Elizabeth O'Keeffe. 2013. Community Biodiversity Management: Promoting resilience and the conservation of plant genetic resources. Abingdon: Routledge. 
Dedeurwaerdere, Tom. 2012. Design principles of successful geneticresource commons for food and agriculture. International Journal of Ecological Economics and Statistics 26 (3): 16-30.

Delgado Aguilar, Natalia. 2016. Community protocols as tools for resisting exclusion in global environmental governance. Revista de Administração de Empresas 56 (4): 395-410.

Diamond, Jared. 1999. Guns, germs and steel: The fates of human societies. New York: WW Norton \& Company.

Donald, Aletheia, Gayatri Koolwal, Jeannie Annan, Kathryn Falb, and Markus Goldstein. 2017. Measuring women's agency. Washington, D.C.: The World Bank.

Döring, Thomas F., Samuel Knapp, Geza Kovacs, Kevin Murphy, and Martin S. Wolfe. 2011. Evolutionary plant breeding in cerealsinto a new era. Sustainability 3 (10): 1944-1971.

Elias, Marianne, Laura Rival, and Doyle McKey. 2000. Perception and management of cassava (Manihot esculenta Crantz) diversity among Makushi Amerindians of Guyana (South America). Journal of Ethnobiology 20 (2): 239-265.

FAO. 2010. The second report on the state of the world's plant genetic resources for food and agriculture. Rome. https://www.fao.org/3/ i1500e/i1500e.pdf. Accessed 10 July 2020.

Fowler, Cary, and Toby Hodgkin. 2004. Plant genetic resources for food and agriculture: Assessing global availability. Annual Review of Environment and Resources 29: 143-179.

Frison, Christine, and Brendan Coolsaet. 2019. Genetic resources for food and agriculture as commons. London: Routledge.

Galluzzi, Gea, Michael Halewood, Isabel López Noriega, and Ronnie Vernooy. 2016. Twenty-five years of international exchanges of plant genetic resources facilitated by the CGIAR genebanks: A case study on global interdependence. Biodiversity and Conservation 25 (8): 1421-1446.

Halewood, Michael, Isabel López Noriega, and Sélim Louafi. 2012. Crop genetic resources as a global commons: Challenges in international law and governance. Abingdon: Routledge.

Halewood, Michael, Elsa Andrieux, Léontine Crisson, Jean Rwihaniza Gapusi, John Wasswa Mulumba, Edmond Kouablan Koffi, Tashi Yangzome Dorji, Madan Raj Bhatta, and Didier Balma. 2013. Implementing mutually supportive access and benefit sharing mechanisms under the plant treaty, convention on biological diversity, and nagoya protocol. Law, Environment and Development Journal 9: 68

Halewood, Michael, Gloria Otieno, Charles Nkhoma, Patrick Kasasa, John Wasswa Mulumba, Jean Rwihaniza Gapusi, and Bram de Jonge. 2017. Access and benefit-sharing policies for climateresilient seed systems. ISSD Synthesis Paper. Nairobi (Kenya): ISSD Africa. $16 \mathrm{p}$

Hardin, Garrett. 1968. The tragedy of the commons. Science 162: 1243-1248.

Hazell, Peter BR. 2005. Is there a future for small farms? Agricultural Economics 32: 93-101.

Hazell, Peter BR. 2007. Transformations in agriculture and their implications for rural development. eJADE: electronic Journal of Agricultural and Development Economics 4: 47-65. https:// doi.org/10.22004/ag.econ.112592.

Hess, Charlotte, and Elinor Ostrom. 2003. Ideas, artifacts, and facilities: Information as a common-pool resource. Law and Contemporary Problems 66 (1/2): 111-145.

Hodgkin, Toby, Nicole Demers, and Emile Frison. 2013. The evolving global system of conservation and use of plant genetic resources for food and agriculture: What is it and where does the Treaty fit in? In Crop genetic resources as a global commons: Challenges in international law and governance, 344-367. London: Earthscan.

Jarvis, Devra I., Toby Hodgkin, Bhuwon Sthapit, Carlo Fadda, and Isabel López Noriega. 2011. An heuristic framework for identifying multiple ways of supporting the conservation and use of traditional crop varieties within the agricultural production system. Critical Reviews in Plant Sciences 30 (1-2): 125-176.

Jarvis, Devra I., Toby Hodgkin, Anthony H. Brown, John D. Tuxill, Isabel López Noriega, Melinda Smale, and Bhuwon Sthapit. 2016. Crop genetic diversity in the field and on the farm: Principles and applications in research practices. London: Yale University Press.

Joint Capacity Building Programme. 2017. Mutually supportive implementation of the Nagoya Protocol and the Plant Treaty: Scenarios for consideration by national focal points and other interested stakeholders. Bioversity International. Rome, Italy. https://ccafs.cgiar.org/publications/mutually-supportive -implementation-nagoya-protocol-and-plant-treaty-scenarios\#. XwdhYSjHzIV. Accessed July 10, 2020.

Joint Capacity Building Programme. 2018. Decision-making tool for national implementation of the Plant Treaty's multilateral system of access and benefit-sharing. Bioversity International, Rome, Italy. https://www.bioversityinternational.org/fileadmin/ user_upload/Decision_Halewood_2018.pdf. Accessed July 10, 2020.

Jonas, Harry, Kabir Bavikatte, and Holly Shrumm. 2010. Community protocols and access and benefit sharing. Asian Biotechnology and Development Review 12 (3): 49-76.

Jones, Richard B., Patrick A. Audi, and Robert Tripp. 2001. The role of informal seed systems in disseminating modern varieties. The example of pigeonpea from a semi-arid area of Kenya. Experimental Agriculture 37 (4): 539-548.

Jukic, Emma, and Neva Collings. 2013. Community protocols for environmental sustainability: A guide for policymakers. UNEP, Nairobi, Kenya. http://wedocs.unep.org/handle/20.500.11822 /8360. Accessed 10 July 2020.

Kabeer, Naila. 1999. Resources, agency, achievements: Reflections on the measurement of women's empowerment. Development and Change 30 (3): 435-464.

Kamau, Evanson Chege, and Gerd Winter. 2013. Common pools of genetic resources: Equity and innovation in international biodiversity law. Abingdon: Routledge.

Kassie, Menale, Bekele Shiferaw, and Geoffrey Muricho. 2010. Adoption and impact of improved groundnut varieties on rural poverty: Evidence from rural Uganda. Discussion Paper Series, EfD-DP 10-11. Environment for Development.

Lassen, Barbara, Lesle Jansen, Jazzy Rasolojaona, Cicilia Githaiga, Lena Fey and Bienvenu Bossou. 2018. Community protocols in Africa: Lessons learned from ABS implementation. Natural Justice and the ABS Capacity Development Initiative. https:// naturaljustice.org/wp-content/uploads/2018/11/2018_Commu nity-Protocols-in-Africa_Lessons-Learned_Natural-Justice.pdf. Accessed 10 July 2020.

Lin, Brenda B. 2011. Resilience in agriculture through crop diversification: Adaptive management for environmental change. BioScience 61 (3): 183-193.

League for Pasturalist Peoples and Endogenous Livestock Development (LPP). 2018. Community protocols for pastoralists and livestock keepers: Claiming rights under the Convention on Biological Diversity. League for Pastoral Peoples and Endogenous Livestock Development, Ober-Ramstadt, Germany). https:// www.pastoralpeoples.org/wp-content/uploads/2018/08/Commu nity-protocols-web.pdf. Accessed July 10, 2020.

López Noriega, Isabel, Michael Halewood, Michael Abberton, Ahmed Amri, Ijantiku Ignatius Angarawai, Noelle Anglin, Michael Blümmel, Bas Bouman, Hugo Campos, and Denise Costich. 2019. CGIAR operations under the plant treaty Framework. Crop Science 59 (3): 819-832.

Louwaars, Niels P. 2007. Seeds of confusion: the impact of policies on seed systems. PhD dissertation, Centre for Genetic Resources, University of Wageningen, The Netherlands. 
Madison, Michael J., Brett M. Frischmann, and Katherine J. Strandburg. 2009. Constructing commons in the cultural environment. Cornell Law Review 95: 657.

Mann, Charles C. 2011. 1493: Uncovering the new world Columbus created. New York: Vintage.

Manzella, Daniele. 2013. The design and mechanics of the multilateral system of access and benefit sharing. In Crop genetic resources as a global commons, 150. Abingdon: Routledge.

McGuire, Shawn, and Louise Sperling. 2016. Seed systems smallholder farmers use. Food Security 8 (1): 179-195.

McMichael, Philip. 1994. The global restructuring of agro-food systems. Ithaca: Cornell University Press.

Mercer, Kristin L., and Hugo R. Perales. 2010. Evolutionary response of landraces to climate change in centers of crop diversity. Evolutionary Applications 3 (5-6): 480-493.

Mijatović, Dunja, Frederik Van Oudenhoven, Pablo Eyzaguirre, and Toby Hodgkin. 2013. The role of agricultural biodiversity in strengthening resilience to climate change: Towards an analytical framework. International Journal of Agricultural Sustainability 11 (2): 95-107.

Montenegro de Wit, Maywa. 2019. Beating the bounds: How does 'open source' become a seed commons? The Journal of Peasant Studies 46 (1): 44-79.

Onwuekwe, Chika B. 2004. The commons concept and intellectual property rights regime: Whither plant genetic resources and traditional knowledge. Pierce Law Review 2: 65.

Ostrom, Elinor. 1990. Governing the commons: The evolution of institutions for collective action. Cambridge: Cambridge University Press.

Otieno, Gloria. 2018. Accessing genetic diversity for food security and climate change adaptation in select communities in Africa. Food Security and Climate Change 19: 499-522.

Otieno, Gloria, Sognigbe N'Danikou, Bienvenu Bossou, Toussaint Mikpon, Raymond Vodouhe, John WM Recha, and Michael Halewood. 2018. Enhancing the capacity of local communities to access crop genetic diversity for climate change adaptation.

Padulosi, Stefano, Toby Hodgkin, John T. Williams, and N. Haq. 2002. Underutilized crops: Trends, challenges and opportunities in the 21 st century, managing plant genetic diversity. Wallingford: $\mathrm{CAB}$ International.

Pimbert, Michel P. 2011. Participatory research and on-farm management of agricultural biodiversity in Europe. London: IIED.

Samberg, Leah H., Carol Shennan, and Erika Zavaleta. 2013. Farmer seed exchange and crop diversity in a changing agricultural landscape in the southern highlands of Ethiopia. Human Ecology 41 (3): 477-485.

Scarascia-Mugnozza, Giacomo T., Pietro Perrino, Johannes Engel, Ramanatha V. Rao, Anthony HD. Brown, and MT. Jackson. 2002. The history of ex situ conservation and use of plant genetic resources. In Managing plant genetic diversity, 1-22. Wallingford: CABI.

Secretariat of the Convention on Biological Diversity (SCBD). 2019. Mo'otz Kuxtal Voluntary Guidelines for the development of mechanisms, legislation or other appropriate initiatives to ensure the "prior and informed consent", "free, prior and informed consent" or "approval and involvement", depending on national circumstances, of indigenous peoples and local communities for accessing their knowledge, innovations and practices, for fair and equitable sharing of benefits arising from the use of their knowledge, innovations and practices relevant for the conservation and sustainable use of biological diversity, and for reporting and preventing unlawful appropriation of traditional knowledge. Montreal, 9 p. (CBD Guidelines Series). https://www.cbd.int/doc/ publications/8j-cbd-mootz-kuxtal-en.pdf. Accessed July 10, 2020.
Shrumm, Holly, and Harry Jonas. 2012. Biocultural community protocols: A toolkit for community facilitators. Cape Town: Natural Justice.

Sperling, Louise, and Shawn McGuire. 2010. Understanding and strengthening informal seed markets. Experimental Agriculture 46 (2): 119-136.

Sthapit, Bhuwon, Pratap Shrestha, and Madhusudan Upadhyay. 2012. Participatory four-cell analysis (FCA) for understanding local crop diversity. In On-farm management of agricultural biodiversity in Nepal. Good Practices, 13-16. NARC/LI-BIRD/ Bioversity International, Nepal.

Thormann, Imke, Johannes MM. Engels, and Michael Halewood. 2019. Are the old International Board for Plant Genetic Resources (IBPGR) base collections available through the Plant Treaty's multilateral system of access and benefit sharing? A review. Genetic Resources and Crop Evolution 66 (2): 291-310.

van Etten, Jacob, Kauê de Sousa, Amílcar Aguilar, Mirna Barrios, Allan Coto, Matteo Dell'Acqua, Carlo Fadda, Yosef Gebrehawaryat, Jeske van de Gevel, and Arnab Gupta. 2019. Crop variety management for climate adaptation supported by citizen science. Proceedings of the National Academy of Sciences 116 (10): 4194-4199.

Varshney, Rajeev K., Chris Ojiewo, and Emmanuel Monyo. 2019. A decade of Tropical Legumes projects: Development and adoption of improved varieties, creation of market-demand to benefit smallholder farmers and empowerment of national programmes in subSaharan Africa and South Asia. Plant Breeding 138 (4): 379-388.

Vernooy, Ronnie, Guy Bessette, and Gloria Otieno. 2019. Resilient seed systems: Handbook. Rome: Bioversity International.

Vigouroux, Yves, Adeline Barnaud, Nora Scarcelli, and Anne-Celine. Thuillet. 2011. Biodiversity, evolution and adaptation of cultivated crops. Comptes Rendus Biologies 334 (5-6): 450-457.

Westengen, Ola Tveitereid, Kristine Skarbø, Teshome Hunduma Mulesa, and Trygve Berg. 2018. Access to genes: Linkages between genebanks and farmers' seed systems. Food Security 10 (1): 9-25.

Westley, Frances R., Ola Tjornbo, Lisen Schultz, Per Olsson, Carl Folke, Beatrice Crona, and Örjan. Bodin. 2013. A theory of transformative agency in linked social-ecological systems. Ecology and Society. https://doi.org/10.5751/ES-05072-180327.

Wirz, Johannes, Peter Kunz, and Ueli Hurter. 2017. Seed as a Commons: Breeding as a Source for Real Economy, Law and Culture: Assessment and Future Perspectives for Non-profit Sseed and Breeding Initiatives. Dornach: Goetheanum.

World Benchmarking Alliance. 2019. Access to Seeds Index 2019. Bridging the gap between the world's leading seed companies and the smallholder farmer. Synthesis report. https://www.accesstose eds.org/app/uploads/2019/06/Access-to-Seeds-2019-Index-Synth esis-Report.pdf. Accessed July 10, 2020.

Publisher's Note Springer Nature remains neutral with regard to jurisdictional claims in published maps and institutional affiliations.

Michael Halewood Team leader, Genetic Resources and Seed Systems Policies, at the Alliance of Bioversity International and the International Center for Tropical Agriculture (CIAT).

Ana Bedmar Villanueva Consultant, Genetic Resources and Seed Systems Policies, at the Alliance of Bioversity International and the International Center for Tropical Agriculture (CIAT).

Jazzy Rasolojaona Programme Manager, at the Francophone Africa Hub of Natural Justice (Lawyers for the environment and communities), Madagascar. 
Michelle Andriamahazo Technical officer, at the Environment, Climate and Emergency Response Service of the Ministry of Agriculture, Livestock and Fisheries, Antananarivo, Madagascar.

Naritiana Rakotoniaina Executive Director of the Environmental Management Support Service (SAGE), and teacher/researcher at the Ambositra Institute of Technologies and at the Higher School of Agronomic Sciences of the University of Antananarivo, Madagascar.

Bienvenu Bossou Executive Director of the NGO CeSaReN, Bonou, Benin.

Toussaint Mikpon Head of Monitoring, Evaluation, Communication and Documentation Service, at the Agricultural Research Center of the National Institute of Agricultural Research of Benin, Ministry of Agriculture, Benin.

Raymond Vodouhe Honorary Research Fellow, at the Alliance of Bioversity International and the International Center for Tropical Agriculture (CIAT).

Lena Fey Project officer. Coordinator of activities in Benin and Côte d'Ivoire, at the ABS Capacity Development Initiative.

Andreas Drews Programme Manager, at the ABS Capacity Development Initiative.

P. Lava Kumar Head of Germplasm Health Unit/Virologist, at the International Institute of Tropical Agriculture.
Bernadette Rasoanirina Chair of the Board of the FaMA Cooperative, Analavory, Madagascar.

Thérèse Rasoazafindrabe Threasurer of the Board of the FaMA Cooperative, Analavory, Madagascar.

Marcellin Aigbe President of the NGO Jeunesse Sans Frontières and Representative of indigenous populations, Benin.

Blaise Agbahounzo Farmer, President of the farmers of Tori-Bossito, Benin.

Gloria Otieno Genetic Resources and Food Security Policy Specialist, at the Alliance of Bioversity International and the International Center for Tropical Agriculture (CIAT).

Kathryn Garforth Legal Officer, Biosafety Unit, at the Secretariat of the Convention on Biological Diversity.

Tobias Kiene Technical Officer, at the Secretariat of the International Treaty of Plant Genetic Resources for Food and Agriculture.

Kent Nnadozie Secretary of the International Treaty of Plant Genetic Resources for Food and Agriculture. 